\title{
Market Excess Returns, Variance and the Third Cumulant
}

\author{
Eric C. Chang \\ Faculty of Business and Economics \\ The University of Hong Kong \\ Pokfulam Road, Hong Kong \\ Email: ecchang@hku.hk \\ Jin E. Zhang ${ }^{1}$ \\ Department of Accountancy and Finance \\ Otago Business School, University of Otago \\ Dunedin 9054, New Zealand \\ Email: jin.zhang@otago.ac.nz \\ Huimin Zhao \\ Sun Yat-Sen Business School \\ Sun Yat-Sen University \\ Guangzhou, P. R. China \\ Email: zhaohuim@sysu.edu.cn
}

First Version: July 2010

This Version: January 2015

Keywords: Equilibrium asset pricing model; Market excess return; Variance; The third cumulant; Variance risk premium

JEL Classification Code: G12; G13

\footnotetext{
${ }^{1}$ Corresponding author. Tel: 643479 8575. Jin E. Zhang has been supported by an establishment grant from University of Otago.
} 


\title{
Market Excess Returns, Variance and the Third Cumulant
}

\begin{abstract}
In this paper, we develop an equilibrium asset pricing model for the market excess return, variance and the third cumulant by using a jump-diffusion process with stochastic variance and jump intensity in Cox, Ingersoll and Ross' (1985) production economy. Empirical evidence with S\&P 500 index and options from January 1996 to December 2005 strongly supports our model prediction that lower the third cumulant, higher the market excess returns. Consistent with existing literature, the theoretical mean-variance relation is supported only by regressions on risk-neutral variance. We further demonstrate empirically that the third cumulant explains significantly the variance risk premium.
\end{abstract}




\section{Introduction}

The third cumulant or skewness has been shown to be an important factor that drives future cross-sectional stock returns. Chang, Christoffersen and Jacobs (2013) demonstrate that stocks with high exposure to innovations in implied market skewness exhibit low returns on average. Conrad, Dittmar and Ghysels (2013) find more ex ante negatively (positively) skewed returns yield subsequent higher (lower) returns. However, there is no existing research studying the importance of the third cumulant in time-series market excess returns. This paper fills the gap by developing an equilibrium model for the market excess return, variance and the third cumulant, and testing the model empirically.

Following Cox, Ingersoll and Ross (1985), Dumas (1989), Vasicek (2005), and Zhang, Zhao and Chang (2012), we establish our equilibrium asset pricing model in a production economy. The production variable or the price of market portfolio follows a jump-diffusion process with stochastic variance and stochastic jump intensity. Solving optimal control problem of one representative investor with CRRA utility function gives us an equilibrium condition for the instantaneous equity premium. Our setup is an extension of Zhang, Zhao and Chang (2012) from contant variance and jump intensity to stochastic ones. The dynamic setting allows us to study the time-series relationship between market excess returns and risk that is measured not only by variance but also by the third cumulant. Recently, Martin (2013) develops a theory of consumption-based asset pricing with higher cumulants by using cumulant-generating function technique. However, it is not possible studying time-series relationship between risk and return using his model because its return distribution is static. To the best of our knowledge, our equilibrium model is the first one that is capable of 
capturing the dynamic relationship between market excess returns and higher cumulants.

With some further analysis, we establish a relationship between term market excess return and term variance and term third cumulant, where the term variance is an aggregate effect between mean variance and mean jump intensity during the period, and the term third cumulant is proportional to the mean jump intensity. Our theoretical model has following testable predictions: higher (lower) the variance (third cumulant), higher the market excess returns. Our theory is further tested empirically by using S\&P 500 index and options data from January 4, 1996 to December 30, 2005

The research on testing mean-variance relationship of market portfolio is controversial. Campbell (1987), and Glosten, Jagannathan and Runkle (1993) document that the conditional volatility and the risk premium are negatively related, contrary to economic theory, while Turner, Startz and Nelson (1989), and Harrison and Zhang (1999) find a positive relation between them. Using a VAR technique, Brandt and Kang (2004) document that conditional correlation between mean and volatility is negative and the unconditional correlation is positive. Recently, Guo and Whitelaw (2006) find that market returns are positively related to implied volatilities. Banerjee, Doran and Peterson (2007) also document that implied volatility of the market has predictive power for future return on portfolios even controlling with Fama and French risk factors. Consistent with the existing literature, we find that the standard theoretical mean-variance relationship is supported by regressions on risk-neutral variance based on monthly and quarterly returns, but not supported by those on physical variance.

Our theory on the relation between market excess returns and the third cumulant 
is strongly supported by empirical evidence. Combining the third central moments as another risk factor with variance, we find that all of the intertemporal and contemporaneous relations between market excess returns and the third cumulant are significantly negative for quarterly, semiannual and annual return regressions. Even combined with other predicting variables, such as $\mathrm{P} / \mathrm{D}$ ratio, the default spread and the consumption-wealth ratio (CAY), the coefficients of ex-post, risk-neutral and contemporaneous third cumulant of market returns are negatively significant. Our research shows that the third cumulant should be included as a measure of risk in addition to variance when investigating risk-return relation.

Consistent with Bollerslev, Tauchen and Zhou (2009), we find that variance risk premia (VRP) are negatively related to the future market excess returns. Futher examining its source, we find that the third cumulant contributes to VRP. The potential link between market excess returns and VRP might be due to the third cumulant. Our observation is consistent with Bakshi and Madan's (2006) theory that connects volatility spread (risk-neutral minus physical volatility) to the third and fourth cumulants of returns, and parameters of the pricing kernel.

The rest of this paper is organized as follows. Section 2 provides our theoretical model on the relationship between market excess return, variance and the third cumulant. Section 3 describes the measurement of variables. Section 4 describes data used. Section 5 presents our empirical results. Section 6 concludes.

\section{Model}

Following Cox, Ingersoll and Ross (1985), Dumas (1989), Vasicek (2005), and Zhang, Zhao and Chang (2012), we establish our equilibrium asset pricing model in a production economy. There is a single aggregate stock that is understood as a stock 
index or a market portfolio. We assume that the stock price, $S_{t}$, follows a stochastic differential equation with a stochastic variance, $V_{t}$, and jump intensity, $\lambda_{t}$, as follows

$$
\begin{aligned}
\frac{d S_{t}}{S_{t}} & =\mu_{t} d t+\sqrt{V_{t}} d B_{t}^{S}+\left(e^{x}-1\right) d N_{t}-\lambda_{t} E\left(e^{x}-1\right) d t \\
d V_{t} & =\kappa_{V}\left(\theta_{V}-V_{t}\right) d t+\sigma_{V} \sqrt{V_{t}} d B_{t}^{V} \\
d \lambda_{t} & =\kappa_{\lambda}\left(\theta_{\lambda}-\lambda_{t}\right) d t+\sigma_{\lambda} \sqrt{\lambda_{t}} d B_{t}^{\lambda} .
\end{aligned}
$$

where $\mu_{t}$ is the instantaneous expected return, $d B_{t}^{S}, d B_{t}^{V}$ and $d B_{t}^{\lambda}$ denote the increments of three standard Brownian motions, $d N_{t}$ is the increment of a Poisson process with jump intensity $\lambda_{t}$, i.e., $E\left(d N_{t}\right)=\lambda_{t} d t$, and jump size $x$ that follows an arbitrary distribution. We further assume that the stock return is correlated with variance process with a constant coefficient $\rho$, but both stock return and variance are independent of jump intensity process, that is

$$
E\left[d B_{t}^{S} d B_{t}^{V}\right]=\rho d t, \quad E\left[d B_{t}^{S} d B_{t}^{\lambda}\right]=E\left[d B_{t}^{V} d B_{t}^{\lambda}\right]=0
$$

We further assume that there is a money market, $M_{t}$, that follows the dynamics

$$
\frac{d M_{t}}{M_{t}}=r_{t} d t
$$

Investors can instantaneously borrow and lend at a risk-free rate, $r_{t}$, in the money market.

A representative investor seeks to maximize the expected utility function of his life time consumption

$$
\max _{c_{t}} E_{t} \int_{t}^{+\infty} e^{-\beta(s-t)} U\left(c_{s}\right) d s
$$

where $c_{t}$ is the rate of consumption at time $t, U(c)$ is a utility function with $U^{\prime}>0$, $U^{\prime \prime}<0$, and $e^{-\beta(s-t)}, s \geq t$ is a time preference function. We consider the class of 
constant relative risk aversion (CRRA) utility function

$$
U(c)= \begin{cases}\frac{c^{1-\gamma}}{1-\gamma}, & \gamma>0, \gamma \neq 1, \\ \ln c, & \gamma=1,\end{cases}
$$

where the constant $\gamma$ is the relative risk aversion coefficient, $\gamma=-c U^{\prime \prime} / U^{\prime}$.

The total wealth of the representative investor at time $t$ is written as

$$
W_{t}=W_{1 t}+W_{2 t}
$$

where $W_{1 t}=\omega W_{t}$ is the wealth invested in the stock market ( $\omega$ being the wealth ratio) and $W_{2 t}=(1-\omega) W_{t}$ is the wealth invested in the money market.

The representative investor's optimal control problem becomes

$$
\max _{\left(c_{t}, \omega\right)} E_{t} \int_{t}^{+\infty} e^{-\beta(s-t)} U\left(c_{s}\right) d s
$$

subject to

$$
\frac{d W_{t}}{W_{t}}=\left[r_{t}+\omega \phi_{t}-\omega \lambda_{t} E\left(e^{x}-1\right)-\frac{c_{t}}{W_{t}}\right] d t+\omega \sqrt{V_{t}} d B_{t}^{S}+\omega\left(e^{x}-1\right) d N_{t},
$$

where $\phi_{t} \equiv \mu_{t}-r_{t}$ is the instantaneous expected excess return. The consumption rate $c_{t}$ and the wealth ratio $\omega$ are control variables. Because there is only one investor in the economy, he would have to put all his wealth in the production (stock market). The general equilibrium occurs at $\omega=1$, under which the market is cleared.

After solving the optimal control problem, we have following Proposition.

Proposition 1 In the production economy with stock price process given in (1) and one representative investor with CRRA utility function, the instantaneous expected excess return at time $t$ is given by

$$
\phi_{t} \equiv \mu_{t}-r_{t}=\left(\gamma-\rho \sigma_{V} B\right) V_{t}+\lambda_{t} E\left[\left(e^{x}-1\right)\left(1-e^{-\gamma x}\right)\right]
$$


where $B$ together with two other constants, $A$ and $C$, are determined by a set of three equations as follows

$$
\begin{aligned}
r(1-\gamma)-\beta+\kappa_{V} \theta_{V} B+\kappa_{\lambda} \theta_{\lambda} C+\gamma e^{-\frac{1}{\gamma}\left(A+B \theta_{V}+C \theta_{\lambda}\right)}\left(1+\frac{1}{\gamma} B \theta_{V}+\frac{1}{\gamma} C \theta_{\lambda}\right) & =0, \\
\frac{1}{2} \gamma(1-\gamma)-\kappa_{V} B+\frac{1}{2} B^{2} \sigma_{V}^{2}-B e^{-\frac{1}{\gamma}\left(A+B \theta_{V}+C \theta_{\lambda}\right)} & =0, \\
(1-\gamma) E\left(e^{-\gamma x}\right)+\gamma E\left[e^{(1-\gamma) x}\right]-1-\kappa_{\lambda} C+\frac{1}{2} C^{2} \sigma_{\lambda}^{2}-C e^{-\frac{1}{\gamma}\left(A+B \theta_{V}+C \theta_{\lambda}\right)} & =0 .
\end{aligned}
$$

Proof. See Appendix A.

Remark 1.1: Equation (8) captures the relationship between instantaneous excess return and instantaneous variance and jump intensity. It is an extension of Zhang, Zhao and Change (2012) from constant to stochastic volatility and jump intensity.

Remark 1.2: Expanding the second term at right-hand-side for small jump size, $x$, gives us

$$
\begin{aligned}
\phi_{t} & =\left(\gamma-\rho \sigma_{V} B\right) V_{t}+\sum_{n=2}^{+\infty} \frac{1}{n !}\left[1+(-1)^{n} \gamma^{n}-(1-\gamma)^{n}\right] \lambda_{t} E\left(x^{n}\right) \\
& =\gamma T V_{t}-\rho \sigma_{V} B V_{t}+\frac{1}{2} \gamma(1-\gamma) T C_{t}+\frac{1}{12} \gamma\left(2-3 \gamma+2 \gamma^{2}\right) F C_{t}+o\left[E\left(x^{4}\right)\right]
\end{aligned}
$$

where $T V_{t}, T C_{t}$ and $F C_{t}$ are instantaneous total variance, the third and fourth cumulants respectively. They are given by

$$
T V_{t}=V_{t}+\lambda_{t} E\left(x^{2}\right), \quad T C_{t}=\lambda_{t} E\left(x^{3}\right), \quad F C_{t}=\lambda_{t} E\left(x^{4}\right) .
$$

If $V_{t}$ and $\lambda_{t}$ are constants, then $\sigma_{V}=0$, our result here reduces to that of Martin (2013) for an arbitrary static distribution. To the best of our knowledge, equation (9) is the first theoretical result on describing the dynamic relationship between instantaneous excess return and instantaneous variance, the third and fourth cumulants. 
In this paper, our purpose is to examine the relationship between market excess return and risk, which is measured by variance and the third cumulant. However, it is very difficult, if not impossible, to evaluate instantaneous variance and third cumulant. Therefore we have to develop a model to describe the relationship between term return, i.e., the return over a period from $t$ to $T$, and term variance and third cumulant.

In physical measure, applying Ito's Lemma with jumps to equation (1) gives a process for the logarithm of stock price as follows

$$
d \ln S_{t}=\left[r_{t}+\phi_{t}-\frac{1}{2} V_{t}-\lambda_{t} E\left(e^{x}-1\right)\right] d t+\sqrt{V_{t}} d B_{t}^{S}+x d N_{t}
$$

The expected term excess return, variance and third cumulant are given by

$$
\begin{aligned}
\operatorname{ExR}_{t, T}^{p} & =E_{t}^{p}\left[\int_{t}^{T}\left(d \ln S_{s}-r_{s} d s\right)\right] \\
& =E_{t}^{p}\left[\int_{t}^{T}\left(\phi_{s}-\frac{1}{2} V_{s}-\lambda_{s} E\left(e^{x}-1-x\right)\right) d s\right] \\
\operatorname{Var}_{t, T}^{p} & =E_{t}^{p}\left[\int_{t}^{T}\left(d \ln S_{s}\right)^{2}\right]=\int_{t}^{T} E_{t}^{p}\left(V_{s}\right) d s+E\left(x^{2}\right) \int_{t}^{T} E_{t}^{p}\left(\lambda_{s}\right) d s \\
T C_{t, T}^{p} & =E_{t}^{p}\left[\int_{t}^{T}\left(d \ln S_{s}\right)^{3}\right]=E\left(x^{3}\right) \int_{t}^{T} E_{t}^{p}\left(\lambda_{s}\right) d s
\end{aligned}
$$

respectively.

With some algebra, we have following proposition.

Proposition 2 The expected term excess return, $\operatorname{Ex}_{t, T}^{p}$, and variance, $\operatorname{Var}_{t, T}^{p}$, and third cumulant, $T C_{t, T}^{p}$, are related by

$$
\operatorname{ExR}_{t, T}^{p}=\beta_{1} \operatorname{Var}_{t, T}^{p}+\beta_{2} T C_{t, T}^{p},
$$


where the coefficients, $\beta_{1}$ and $\beta_{2}$, are given by

$$
\begin{aligned}
& \beta_{1}=\gamma-\rho \sigma_{V} B-\frac{1}{2} \\
& \beta_{2}=\frac{E\left[x+e^{-\gamma x}-e^{(1-\gamma) x}-\left(\gamma-\rho \sigma_{V} B-\frac{1}{2}\right) x^{2}\right]}{E\left(x^{3}\right)} .
\end{aligned}
$$

Proof. See Appendix B.

Remark 2.1: In general, $\beta_{1}$ is positive, $\beta_{2}$ is negative for negative jump size, $x$. For small jump size, $x$, with Taylor expansion, we have $x+e^{-\gamma x}-e^{(1-\gamma) x}-\left(\gamma-\rho \sigma_{V} B-\frac{1}{2}\right) x^{2}=\rho \sigma_{V} B x^{2}-\frac{1}{6}\left(3 \gamma^{2}-3 \gamma+1\right) x^{3}+o\left(x^{4}\right)$.

We know from the previous analysis that $B<0$ and the correlation between the stock price process and volatility process is usually negative, i.e., $\rho<0$. Therefore if the jump size $x$ is negative, both terms in this equation are positive, hence $\beta_{2}$ is negative. For example, taking $\gamma=2, \rho=-0.75, \sigma_{V}=1.79, B=-0.46$ and $x=-0.1$ gives

$$
\beta_{1}=0.88, \quad \beta_{2}=-7.40 \text {. }
$$

Remark 2.2: Equation (13) describes the relationship between risk and return, where the risk is measured by combing future realized variance and third cumulant. Investors prefer a stock with lower variance and higher third cumulant. This buying demand pushes up its current price, makes its return being lower.

At time $t$, the information for the future realized variance and third cumulant is not available, we have to find some other proxy variables such as historical ones calculated from historical stock prices or implied/risk-neutral ones calculated from options price. 
We have two hypotheses that are now available for empirical tests.

Hypothesis 1: Higher the historical or implied/risk-neutral variance, higher the expected return.

Hypothesis 2: Higher the historical or implied/risk-neutral third cumulant, lower the expected return.

\section{$3 \quad$ Variable Measurements}

We denote $t$ as an index for period. There are $n$ days in one period. The physical variance and third cumulant over the period of $(t-1, t)$ are computed as

$$
\begin{aligned}
P h V_{t} & =\sum_{j=1}^{n}\left(\ln \frac{S_{t-1+\frac{j}{n}}}{S_{t-1+\frac{j-1}{n}}}\right)^{2}, \\
P h T_{t} & =\sum_{j=1}^{n}\left(\ln \frac{S_{t-1+\frac{j}{n}}}{S_{t-1+\frac{j-1}{n}}}\right)^{3} .
\end{aligned}
$$

Hence the physical skewness is given by

$$
P h S k_{t}=\frac{P h T_{t}}{\left(P h V_{t}\right)^{3 / 2}} .
$$

We denote $R_{t, t+1}=\ln \frac{S_{t+1}}{S_{t}}$ as one period continuously compounded return, then the implied/risk-neutral variance and third cumulant can be computed by using Bakshi, Kapadia and Madan's (2003) methodology as follows

$$
\begin{aligned}
R n V_{t} & =E_{t}^{Q}\left[\left(R_{t, t+1}-E_{t}^{Q}\left(R_{t, t+1}\right)\right)^{2}\right]=E_{t}^{Q}\left(R_{t, t+1}^{2}\right)-\left[E_{t}^{Q}\left(R_{t, t+1}\right)\right]^{2}, \\
R n T_{t} & =E_{t}^{Q}\left[\left(R_{t, t+1}-E_{t}^{Q}\left(R_{t, t+1}\right)\right)^{3}\right] \\
& =E_{t}^{Q}\left(R_{t, t+1}^{3}\right)-3 E_{t}^{Q}\left(R_{t, t+1}^{2}\right) E_{t}^{Q}\left(R_{t, t+1}\right)+2\left[E_{t}^{Q}\left(R_{t, t+1}\right)\right]^{3},
\end{aligned}
$$

where the right-hand-side can be computed by using current price of European options with all strikes. 


\section{Data Description}

The S\&P 500 index is used as a market portfolio. S\&P 500 index options data from January 4, 1996 to December 30, 2005 is provided by OptionMetrics. We use daily European call and put options price data to compute risk-neutral variance and third cumulant for fixed maturities: 1, 3, 6 and 12 months in the sample period.

In addition to physical and risk-neutral variances and third cumulants, we also consider other more traditional predicting variables used in the literature, see e.g., Bollerslev, Tauchen and Zhou (2009). Specifically, we obtain daily P/E ratios and dividend yields for the S\&P 500 from OptionMetrics. Daily data on the 3-month Tbill, the default spread (between Moody's BAA and AAA corporate bond spreads), the daily term spread (between the 10-year T-bond and the 3-month T-bill yields), and the stochastically daily de-trended risk-free rate (the 1-month T-bill rate minus its backward 12-month moving average) are taken from the website of the Federal Reserve Bank of St. Louis. The data of consumption-wealth ratio (CAY), defined by Lettau and Ludvigson (2001), is downloaded from Lettau and Ludvigson's website.

Table 1 reports a summary statistics and predicting variables based on the annualized daily return. The mean excess return of S\&P 500 index over the period of 3 -month is $3.19 \%$. The sample means for the variance risk premium, physical skewness, physical variance and third cumulant are $-0.89,-3.18,29.53$ and -5.26 respectively. Negative variance risk premium and negative skewness are consistent with literature, see e.g., Bollerslev, Tauchen and Zhou (2009), Bali and Hovakimian (2009), and Zhang, Zhao and Chang (2011). 


\section{Empirical Results}

The main purpose of our empirical study is to investigate the intertemporal and contemporaneous relations between market excess returns, variance and the third cumulant. Our simple linear regressions on the S\&P 500 excess returns are based on different sets of (or lagged) predicting variables with the same time horizon. All of the reported t-statistics are Newey-West adjusted values taking account of the overlap in the regressions. Our discussions focus on the estimated slope coefficients and their statistical significance as determined by the robust t-statistics. At the same time, we also report the corresponding adjusted $R^{2}$ s.

Based on the modeling results in Section 2, we run regressions of market excess returns on lagged/realized/risk-neutral variance, lagged/realized/risk-neutral third cumulant, lagged skewness, variance risk premium and the control variables mentioned in the previous section as follows

$$
\begin{aligned}
\operatorname{ExR}_{t, t+1}= & \alpha+\beta_{1} P h V_{t} / P h V_{t+1} / R n V_{t}+\beta_{2} P h T_{t} / P h T_{t+1} / P h S k_{t} / R n T_{t} \\
& +\beta_{3} V R P_{t}+\beta_{4} \text { Control }_{t}+\epsilon_{t+1} .
\end{aligned}
$$

\subsection{Intertemporal and Contemporaneous Relationship be- tween Market Excess Returns and Variance}

The results for monthly, quarterly, semi-annual and annual returns are reported in Tables 2, 3, 4 and 5 respectively. The "Single" column reports the regression coefficients and Newey-West adjusted t-statistics of the excess returns on single factor only. The "Multiple" column gives the regression results with other control variables. For physical variance, $P h V_{t}$, we find that none of the coefficients is significant for the simple regression. It is not significant either even combined other predicting variables. $R^{2}$ s are also very low, especially for quarterly return regressions (being only $-0.04 \%$ ). 
This indicates that the ex-post or historical variance does not have a predicting power for the future returns.

This phenomenon has been observed by other researchers, including Bollerslev, Tauchen and Zhou (2009), and Diacogiannis and Feldman (2010). The insignificance implies that the past variance contains little information for the future stock returns. It is also consistent with the literature that past or historical variance is not a good or efficient proxy for future variance. In Table 7, we examine the subperiod of the bear market from 24 March 2000 to 9 October 2002, we find that market excess return is positively related to the ex-post variance. As shown in Table 8, for the bull market period from January 1996 to 23 March 2000, the regressions of market excess returns on the ex-post variance is not significant.

The implied volatility (variance) is widely believed to be a good predictor for future volatility (variance), see e.g., Canina and Figlewski (1993), therefore we also run regressions on the implied/risk-neutral variance. For quarterly return regressions in Table 3, the coefficient of risk-neutral variance is 0.89 and t-statistics is 2.86 which have the highest values. When combined with other predictors, such as RREL, $T M S P$, price-earning ratio $\ln (P / E)$ and consumption-wealth ratio $C A Y$, regression on risk-neutral variance is still significant with a t-statisitcs of $2.67 . R^{2}$ also increases from $4.38 \%$ to $20.23 \%$.

Large literature has documented the positive relationship between future market returns and implied volatility. For example, Banerjee, Doran and Peterson (2007) document that implied volatility of the market has predictive power for future return on portfolios even controlling with Fama and French risk factors. Guo and Whitelaw (2006) also find that market returns are positively related to implied volatilities.

There exists no definitive answer on the relationship between mean and volatility 
in the literature. For example, Campbell (1987), and Glosten, Jagannathan and Runkle (1993) document that the conditional volatility and the risk premium are negatively related, contrary to economic theory, while Harrison and Zhang (1999) and Turner, Startz and Nelson (1989) find a positive relation between them. Using a VAR technique, Brandt and Kang (2004) document that conditional correlation between mean and volatility is negative and the unconditional correlation is positive.

In this study, we also explore the contemporaneous relationship between market excess returns and variance. Table 2, 3, 4 and 5 provide the regressions results of the market excess returns on the realized variance in the same period for monthly, quarterly, semi-annul and annual returns. We find that they have a significant negative relation. The coefficients for all the simple regressions are negative and the absolute values of t-statistics are larger than 2. Combined other control variables, such as price-dividend ratio, DFSP, RREL, TMSP and $C A Y$, the regressions on the current variances are still negatively significant. Adding the current third central moments into the regressions, the coefficients of current variance and third central moments are significant, and $R^{2}$ increases from $14.5 \%$ to $16.24 \%$.

The empirical results show that the contemporaneous relationship between market excess returns and variance is significantly negative while the past variance has no predictive power for the future market excess returns.

\subsection{Intertemporal and Contemporaneous Relationship be- tween Market Excess Returns and the Third Cumulant}

Mitton and Vorkink (2007) document the portfolio returns of under-diversified investors are substantially more positively skewed than those of diversified investors. The preference for skewness pushes up the price of the assets with high skewness, so that the market portfolio has a lower return and negative skewness due to its well- 
diversification. Harvey and Siddique (2000a) show that conditional skewness helps explain the cross-sectional variation of expected returns across assets, but they do not study the aggregate market. Harvey and Siddique (2000b) show that the expected market risk premium implied by skewness is negative for world and US portfolio and hence the conditional skewness explains the negative market risk premium, but they do not investigate the relation between market excess returns and the third cumulant.

Using the S\&P 500 index as the proxy of market portfolio, we find that the coefficients on the third cumulant are all negatively significant for quarterly regressions in Table 3. The coefficients of physical third cumulant and skewness range from -0.12 to -0.13 and from -0.23 to -0.26 respectively, which implies an important economic significance. Moreover, the t-statistics are high in absolute value ranging from -1.78 to -3.34. Hence, we observe not only an important economic significance, but also highly statistically significant parameter estimates.

Atilgan, Bali and Demirtas (2010) also investigate the intertemporal relationship between the implied volatility spread and expected returns on the aggregate stock market. They argue that this relation is not driven by information flow from options to stock markets rather than volatility spreads acting as a proxy for skewness. The main reason for this argument is that the regression of excess return with physical skewness as a control variable is not significant. They put all of the control variables together in the regressions. The treatment might decrease or increase the significance of the some factors if the variables are linear correlated. For example, the past variance is highly significant in all of the regressions in their Table 3. This is inconsistent with literature, including Bollerslev, Tauchen and Zhou (2009) and Diacogiannis and Feldman (2010) as we discussed above. We run the regressions with physical skewness not only as an individual factor but also combined with other predictors. All of our 
results on adjusted t-statistics imply that the higher the ex-post skewness, the lower the future excess returns.

We also note that for monthly, quarterly and semi-annual return regressions, the coefficients of the risk-neutral third cumulant are also negatively significant. For the single regressions, the $R^{2}$ s are $1.52 \%, 6.73 \%$ and $5.60 \%$ perspectively. After combining other control variables, we find that $R^{2}$ is also the highest for quarterly return regressions and the coefficients of the risk-neutral third cumulant are also negatively significant.

We also examine the contemporaneous relationship between market excess returns and the third cumulant. The coefficients of current third cumulant are all significant for simple regressions of quarterly, semiannual and annual returns. $R^{2}$ s increases from $5.49 \%, 19.46 \%$ to $33.16 \%$. When combined the variance or other control variables, the values of t-statistics are still large with a larger $R^{2}$ s. Furthermore, we note that from simple regressions, the absolute value of t-statistics is larger for longer return maturity.

Our empirical results show that both of intertemporal and contemporaneous relationships between market excess returns the third cumulant are negative. This means that effect of the third cumulant on market excess returns cannot be neglected. Riskreturn relationship has been generally understood as mean-variance relation. Our research shows that the higher order moments, such as the third cumulant should be included into the risk measurement together with variance.

\subsection{Intertemporal Relationship between Variance Risk Pre- mium and the Third Cumulant}

From the empirical results presented in Tables 2, 3, 4 and $5, R^{2}$ s of simple regressions of quarterly returns on variance risk premium, the third cumulant and skewness 
are $9.08 \%, 7.67 \%$ and $10.40 \%$ respectively. Combined with other predictors such as variance risk premium, price-dividend ratio, the default spread (DFSP) and the relative risk free rate $(R R E L)$, the third cumulant remains statistically significant with $R^{2}$ increased. We find that variance risk premium is significant in the individual regression and the coefficients remain statistically significant in the joint regressions combined other predictors. This is consistent with Bollerslev, Tauchen and Zhou (2009) which document that high (low) variance risk premia predicts high (low) future aggregate stock market returns. We also note that the conditional physical skewness is more significant than the third cumulant for monthly and quarterly regressions even combined other predictors.

From the analysis of previous subsection, we know that both of variance risk premium and the third cumulant have predicting power for the future market excess returns. We now examine whether the third cumulant or skewness have an explanatory power for variance risk premium. Table 6 presents results from the time-series regressions of variance risk premium on the third cumulant as follows

$$
V R P_{t}=\alpha+\beta_{1} P h T_{t} / P h S k_{t}+\beta_{2} \text { Control } V_{t}+\epsilon_{t}
$$

We also run the regressions on the skewness in order to differentiate its role with the third cumulant.

We find that all regressions on the third cumulant for different time horizons are significant. Its coefficients range from 1.21 to 2.99. Almost all of absolute values of the Newey-West adjusted t-statistics are larger than 2. The largest coefficient 2.99 appears in regression of annual returns with a t-statistics being $3.85 . R^{2}$ being $33.98 \%$ is also the highest for the same regression. Even combined with other control variables, such as price-dividend ratio $(\ln (P / D)))$, default spread $(D F S P)$, term speard $(T M S P)$, the relative risk free rate $(R R E L)$ and wealth consumption ratio $(C A Y)$, 
the coefficients of the third cumulant are significant for all regressions. However, we observe that no regression on physical skewness is significant. The result show that variance risk premium contains information from the third cumulant instead of skewness. The physical skewness does not have direct effect on the difference between physical and risk-neutral variance. Therefore, we believe that reason behind a potential relationship between expected returns and volatility spreads observed by Atilgan, Bali and Demirtas (2010) is due to the third cumulant instead of skewness.

\section{Conclusion}

In this paper, we study the relationship between risk and return of market portfolio. Classically risk is measured by using variance of returns. Here we argue that in addition to variance, the third cumulant also plays an important role is measuring the risk, and hence it should be priced as a new risk factor in market portfolio.

To formulate our argument, we develop an equilibrium model to link market excess return with variance and the third cumulant. Based on Cox, Ingersoll and Ross' (1985) production economy, we model the price of market portfolio by using a jump-diffusion process with stochastic variance and stochastic jump intensity. Solving the optimal control problem of one representative investor, we obtain an analytical formula for the equilibrium instantaneous equity premium as a function of instantaneous variance and instantaneous jump intensity. With some further analysis, we establish a relationship between term market excess return and term variance and term third cumulant, where the term variance is an aggregate effect between mean variance and mean intensity during the period, and the term third cumulant is proportional to the mean jump

intensity. Our theoretical model predicts that higher (lower) the variance (third cumulant), higher the market excess return. 
Our empirical study is based the market data from January 4, 1996 to December 30, 2005. We compute market excess return, physical variance and physical third cumulant by using S\&P 500 index as a proxy of market portfolio, and compute riskneutral variance and third cumulant from S\&P 500 index options by using Bakshi, Kapadia and Madan's (2003) methodology. Uni- and multi-variate regressions show that our theoretical prediction on the relation between market excess return and the third cumulant is supported by empirical evidence with a proxy from any of historical, realized and risk-neutral variables. Consistent with many existing empirical research, we find that the standard theory on mean-variance relation is not supported by regressions on physical variance. It is supported only regressions of monthly and quarterly returns on risk-neutral variance.

Consistent with literature, we find that variance risk premium has significant explanatory power for the future stock returns. We further explore its source and find that the third cumulant explains more than $30 \%$ of the variance risk premium based on annual returns. This observation further confirms that the third cumulant is an important risk factor that drives the premia in equity and variance. 


\section{A Proof of proposition 1}

The representative investor's problem is to determine an optimal consumption and investment strategy, i.e., $c_{t}$ and $\omega$, in order to maximize his expected utility of his life time consumption. The optimal indirect utility is assumed to be

$$
J\left(W_{t}, V_{t}, \lambda_{t}, t\right)=\max _{\left(c_{t}, \omega\right)} E_{t} \int_{t}^{+\infty} e^{-\beta(s-t)} U\left(c_{s}\right) d s .
$$

The condition of optimality is given by the Bellman equation

$$
E_{t}[d J+(U(c)-\beta J) d t]=0 .
$$

Applying Ito's Lemma with jumps gives

$$
\begin{aligned}
d J= & J_{t} d t+J_{W}\left[r_{t}+\omega \phi_{t}-\omega \lambda_{t} E\left(e^{x}-1\right)\right] W d t-J_{W} c d t+J_{V} \kappa_{V}\left(\theta_{V}-V_{t}\right) d t \\
& +J_{\lambda} \kappa_{\lambda}\left(\theta_{\lambda}-\lambda_{t}\right) d t+\frac{1}{2} J_{W W} W^{2} \omega^{2} V_{t} d t+\frac{1}{2} J_{V V} \sigma_{V}^{2} V_{t} d t+\frac{1}{2} J_{\lambda \lambda} \sigma_{\lambda}^{2} \lambda_{t} d t \\
& +J_{W V} W \rho \omega \sigma_{V} V_{t} d t+J_{W} W \omega \sqrt{V_{t}} d B_{t}^{S}+J_{V} \sigma_{V} \sqrt{V_{t}} d B_{t}^{V}+J_{\lambda} \sigma_{\lambda} \sqrt{\lambda_{t}} d B_{t}^{\lambda} \\
& +\left[J\left(W\left(1+\omega\left(e^{x}-1\right)\right), t\right)-J(W, t)\right] d N_{t},
\end{aligned}
$$

where the subscripts of $J$ stands for partial derivatives. Taking conditional expectation $E_{t}$ against $d J$ yields following equation

$$
\begin{aligned}
& \max _{\left(c_{t}, \omega\right)}\left\{J_{t}+\left[r_{t}+\omega \phi_{t}-\omega \lambda_{t} E\left(e^{x}-1\right)\right] W J_{W}-J_{W} c+J_{V} \kappa_{V}\left(\theta_{V}-V_{t}\right)\right. \\
& +J_{\lambda} \kappa_{\lambda}\left(\theta_{\lambda}-\lambda_{t}\right)+\frac{1}{2} J_{W W} W^{2} \omega^{2} V_{t}+J_{W V} W \rho \omega \sigma_{V} V_{t}+\frac{1}{2} \sigma_{V}^{2} V_{t} J_{V V}+\frac{1}{2} \sigma_{\lambda}^{2} \lambda_{t} J_{\lambda \lambda} \\
& \left.\quad+\lambda E\left[J\left(W\left(1+\omega\left(e^{x}-1\right)\right), t\right)\right]-\lambda_{t} J(W, t)\right\}+U(c)-\beta J=0 .
\end{aligned}
$$

Since the equation is true for the optimal $\left(c_{t}, \omega\right)$, we take a partial derivative of this equation with respect to $c_{t}$ and $\omega$ and obtain the first order conditions

$$
\begin{aligned}
& -J_{W}+U^{\prime}(c)=0, \\
& {\left[\phi_{t}-\lambda_{t} E\left(e^{x}-1\right)\right] W J_{W}+\omega V_{t} W^{2} J_{W W}+\rho \sigma_{V} V_{t} W J_{W V}} \\
& \quad+\lambda_{t} E\left[J_{W}\left(W\left(1+\omega\left(e^{x}-1\right)\right), t\right) W\left(e^{x}-1\right)\right]=0 .
\end{aligned}
$$


Applying the market clearing condition $\omega=1$ to the second equation gives the equilibrium instantaneous expected excess return $\phi_{t}$ in terms of the optimal indirect utility function $J(W, t)$ as follows

$$
\phi_{t}=-V_{t} \frac{W J_{W W}}{J_{W}}-\rho \sigma_{V} V_{t} \frac{J_{W V}}{J_{W}}+\lambda_{t} E\left(e^{x}-1\right)-\lambda_{t} \frac{1}{J_{W}} E\left[J_{W}\left(W e^{x}, t\right)\left(e^{x}-1\right)\right] .
$$

Substituting equation (21) into the Bellman equation (18) gives a integro-partial differential equation for $J(W, t)$

$$
\begin{gathered}
r_{t} W J_{W}-\frac{1}{2} V_{t} W^{2} J_{W W}+J_{V} \kappa_{V}\left(\theta_{V}-V_{t}\right)+\frac{1}{2} J_{V V} \sigma_{V}^{2} V_{t}+J_{\lambda} \kappa_{\lambda}\left(\theta_{\lambda}-\lambda_{t}\right)+\frac{1}{2} J_{\lambda \lambda} \sigma_{\lambda}^{2} \lambda_{t} \\
-\lambda_{t} W E\left[J_{W}\left(W e^{x}, t\right)\left(e^{x}-1\right)\right]+\lambda_{t} E\left[J\left(W e^{x}, t\right)\right]-\left(\lambda_{t}+\beta\right) J-J_{W} c+U(c)=0,(22)
\end{gathered}
$$

where the optimal consumption rate is determined by equation (19).

We now discuss two cases for the value of $\gamma$.

\section{A.1 $\gamma>0$ and $\gamma \neq 1$}

If $\gamma>0$ and $\gamma \neq 1$, the utility function is

$$
U(c)=\frac{c^{1-\gamma}}{1-\gamma}
$$

To solve for $J\left(W_{t}, V_{t}, \lambda_{t}, t\right)$, we conjecture that

$$
J\left(W_{t}, V_{t}, \lambda_{t}\right)=Q\left(V_{t}, \lambda_{t}\right) \frac{W_{t}^{1-\gamma}}{1-\gamma} .
$$

Then the expected excess return (21) can be expressed by

$$
\phi_{t}=\left[\gamma-\rho_{1} \sigma_{V} \frac{Q_{V}}{Q}\right] V_{t}+\lambda_{t} E\left[\left(e^{x}-1\right)\left(1-e^{-\gamma x}\right)\right]
$$

We then solve for the optimal consumption

$$
-J_{W}+U^{\prime}(c)=0, \quad \Longrightarrow \quad Q W^{-\gamma}=c^{-\gamma}, \quad \Longrightarrow \quad c=\left(\frac{1}{Q}\right)^{1 / \gamma} W
$$


Substituting into equations (22) gives

$$
a Q+\kappa_{V}\left(\theta_{V}-V\right) Q_{V}+\frac{1}{2} \sigma_{V}^{2} V Q_{V V}+\kappa_{\lambda}\left(\theta_{\lambda}-\lambda\right) Q_{\lambda}+\frac{1}{2} \sigma_{\lambda}^{2} \lambda Q_{\lambda \lambda}+\gamma Q\left(\frac{1}{Q}\right)^{1 / \gamma}=0
$$

where $a$ is given by

$$
a=r_{t}(1-\gamma)+\frac{1}{2} \gamma(1-\gamma) V_{t}+\lambda_{t}(1-\gamma) E\left(e^{-\gamma x}\right)+\lambda_{t} \gamma E\left[e^{(1-\gamma) x}\right]-\lambda_{t}-\beta
$$

To solve the model, we approximate $Q$ with an exponential affine function as follows

$$
Q\left(V_{t}, \lambda_{t}\right)=e^{A+B V_{t}+C \lambda_{t}}
$$

Substituting equation (27) into (26) gives,

$$
a+\kappa_{V}\left(\theta_{V}-V_{t}\right) B+\frac{1}{2} B^{2} \sigma_{V}^{2} V_{t}+\kappa_{\lambda}\left(\theta_{\lambda}-\lambda_{t}\right) C+\frac{1}{2} C^{2} \sigma_{\lambda}^{2} \lambda_{t}+\gamma e^{-\frac{1}{\gamma}\left(A+B V_{t}+C \lambda_{t}\right)}=0 .
$$

Using Taylor's formula, we expand the exponential term in $V_{t}$ and $\lambda_{t}$ near their long term mean levels, $\theta_{V}$ and $\theta_{\lambda}$, and collect the terms with the same power of $V_{t}$ and $\lambda_{t}$. Because (28) holds for any values of $V_{t}$ and $\lambda_{t}$, all the coefficients must be equal zero, we then have

$$
\begin{aligned}
r(1-\gamma)-\beta+\kappa_{V} \theta_{V} B+\kappa_{\lambda} \theta_{\lambda} C+\gamma e^{-\frac{1}{\gamma}\left(A+B \theta_{V}+C \theta_{\lambda}\right)}\left(1+\frac{1}{\gamma} B \theta_{V}+\frac{1}{\gamma} C \theta_{\lambda}\right) & =0, \\
\frac{1}{2} \gamma(1-\gamma)-\kappa_{V} B+\frac{1}{2} B^{2} \sigma_{V}^{2}-B e^{-\frac{1}{\gamma}\left(A+B \theta_{V}+C \theta_{\lambda}\right)} & =0(29) \\
(1-\gamma) E\left(e^{-\gamma x}\right)+\gamma E\left[e^{(1-\gamma) x}\right]-1-\kappa_{\lambda} C+\frac{1}{2} C^{2} \sigma_{\lambda}^{2}-C e^{-\frac{1}{\gamma}\left(A+B \theta_{V}+C \theta_{\lambda}\right)} & =0 .
\end{aligned}
$$

The expected excess return in (21) can be written as follows:

$$
\phi_{t}=\left[\gamma-\rho \sigma_{V} B\right] V_{t}+\lambda_{t} E\left[\left(e^{x}-1\right)\left(1-e^{-\gamma x}\right)\right] .
$$

To gain some intuitions on the value of $B$, we use following sample set of parameters

$$
\begin{aligned}
& r=0.04, \quad \gamma=2, \quad \beta=0.05, \quad x=-0.08, \\
& \kappa_{V}=1.2101, \quad \theta_{V}=0.55, \quad \sigma_{V}=1.79, \\
& \kappa_{\lambda}=1.2145, \quad \theta_{\lambda}=0.5, \quad \sigma_{\lambda}=0.08 .
\end{aligned}
$$


Solving the set of three equations (29) numerically gives

$$
A=3.2291, \quad B=-0.4602, \quad C=0.0029 .
$$

\section{A.2 $\gamma=1$}

If $\gamma=1$, the utility function is

$$
U(c)=\ln c
$$

The solution of $J\left(W_{t}, V_{t}, \lambda_{t}\right)$ is assumed to have the form

$$
J\left(W_{t}, V_{t}, \lambda_{t}\right)=Q\left(V_{t}, \lambda_{t}\right) \ln W_{t}+G\left(V_{t}, \lambda_{t}\right)
$$

We then solve for the optimal consumption

$$
-J_{W}+U^{\prime}(c)=0, \quad \Longrightarrow \quad Q \frac{1}{W}=\frac{1}{c}, \quad \Longrightarrow \quad c=\frac{1}{Q} W
$$

Substituting into equations (22) gives

$$
\begin{aligned}
& b Q+\ln W\left[\kappa_{V}\left(\theta_{V}-V_{t}\right) Q_{V}+\frac{1}{2} \sigma_{V}^{2} V_{t} Q_{V V}+\kappa_{\lambda}\left(\theta_{\lambda}-\lambda_{t}\right) Q_{\lambda}+\frac{1}{2} \sigma_{\lambda}^{2} \lambda_{t} Q_{\lambda \lambda}-\beta Q+1\right] \\
& +G_{V} \kappa_{V}\left(\theta_{V}-V_{t}\right)+G_{\lambda} \kappa_{\lambda}\left(\theta_{\lambda}-\lambda_{t}\right)+\frac{1}{2} \sigma_{V}^{2} V_{t} G_{V V}+\frac{1}{2} \sigma_{\lambda}^{2} \lambda_{t} G_{\lambda \lambda}-\beta G-1-\ln Q=0,
\end{aligned}
$$

where $b$ is given by

$$
b=r_{t}+\frac{1}{2} V_{t}-\lambda E\left[1-x-e^{-x}\right] .
$$

Because equation (33) always holds for any $W$, we have

$$
\begin{aligned}
& \kappa_{V}\left(\theta_{V}-V_{t}\right) Q_{V}+\frac{1}{2} \sigma_{V}^{2} V_{t} Q_{V V}+\kappa_{\lambda}\left(\theta_{\lambda}-\lambda_{t}\right) Q_{\lambda}+\frac{1}{2} \sigma_{\lambda}^{2} \lambda_{t} Q_{\lambda \lambda}-\beta Q+1=0 \\
& \kappa_{V}\left(\theta_{V}-V_{t}\right) G_{V}+\frac{1}{2} \sigma_{V}^{2} V_{t} G_{V V}+\kappa_{\lambda}\left(\theta_{\lambda}-\lambda_{t}\right) G_{\lambda}+\frac{1}{2} \sigma_{\lambda}^{2} \lambda G_{\lambda \lambda}-\beta G-1+b Q-\ln Q=0 .
\end{aligned}
$$

We also approximate $Q\left(V_{t}, \lambda_{t}\right)$ with an exponential affine function

$$
Q\left(V_{t}, \lambda_{t}\right)=e^{A+B V_{t}+C \lambda_{t}}
$$


Substituting (35) into (34) gives

$$
-\beta+\kappa_{V}\left(\theta_{V}-V_{t}\right) B+\frac{1}{2} B^{2} \sigma_{V}^{2} V_{t}+\kappa_{\lambda}\left(\theta_{\lambda}-\lambda_{t}\right) C+\frac{1}{2} C^{2} \sigma_{\lambda}^{2} \lambda_{t}+e^{-\left(A+B V_{t}+C \lambda_{t}\right)}=0,
$$

which is a special case of equation (28) with $\gamma=1$, can be solved with affine approximation method as before.

The expected instantaneous excess return in (21) is then written as

$$
\phi_{t}=\left[1-\rho \sigma_{V} B\right] V_{t}+\lambda_{t} E\left[\left(e^{x}-1\right)\left(1-e^{-\gamma x}\right)\right] .
$$

\section{B Proof of proposition 2}

Substituting equation (8) into (10) gives

$$
\begin{aligned}
E x R_{t, T}^{p}= & E_{t}^{p}\left[\int_{t}^{T}\left(\phi_{s}-\frac{1}{2} V_{s}-\lambda_{s} E\left(e^{x}-1-x\right)\right) d s\right] \\
= & E_{t}^{p}\left[\int_{t}^{T}\left(\left(\gamma-\rho \sigma_{V} B\right) V_{s}+\lambda_{s} E\left[\left(e^{x}-1\right)\left(1-e^{-\gamma x}\right)\right]-\frac{1}{2} V_{s}-\lambda_{s} E\left(e^{x}-1-x\right)\right) d s\right] \\
= & \left(\gamma-\rho \sigma_{V} B-\frac{1}{2}\right) \int_{t}^{T} E_{t}^{p}\left(V_{s}\right) d s+E\left[x+e^{-\gamma x}-e^{(1-\gamma) x}\right] \int_{t}^{T} E_{t}^{p}\left(\lambda_{s}\right) d s \\
= & \left(\gamma-\rho \sigma_{V} B-\frac{1}{2}\right)\left[\int_{t}^{T} E_{t}^{p}\left(V_{s}\right) d s+E\left(x^{2}\right) \int_{t}^{T} E_{t}^{p}\left(\lambda_{s}\right) d s\right] \\
& +E\left[x+e^{-\gamma x}-e^{(1-\gamma) x}-\left(\gamma-\rho \sigma_{V} B-\frac{1}{2}\right) x^{2}\right] \int_{t}^{T} E_{t}^{p}\left(\lambda_{s}\right) d s \\
= & \beta_{1} \operatorname{Var}_{t, T}^{p}+\beta_{2} T C_{t, T}^{p},
\end{aligned}
$$

where

$$
\begin{aligned}
& \beta_{1}=\gamma-\rho \sigma_{V} B-\frac{1}{2} \\
& \beta_{2}=\frac{E\left[x+e^{-\gamma x}-e^{(1-\gamma) x}-\left(\gamma-\rho \sigma_{V} B-\frac{1}{2}\right) x^{2}\right]}{E\left(x^{3}\right)} .
\end{aligned}
$$




\section{References}

[1] Aitlgan, Yigit, Turan G. Bali, and K. Ozgur Demirtas, 2010, Implied volatility spreads, skewness and expected market returns, Working paper, Georgetown University.

[2] Bakshi, Gurdip, Kapadia, Nikunj, and Dilip Madan, 2003, Stock return characteristic, skew laws, and the differential pricing of individual equity options, Review of Financial Studies 16, 101-143.

[3] Bakshi, Gurdip, and Dilip Madan, 2006, Theory of volatility spread, Management Science 52, 1945-1956.

[4] Bali, Turan G., and Armen Hovakimian, 2009, Volatility spreads and expected stock returns, Management Science 55, 1797-1812.

[5] Banerjee, Prithviraj S., James Doran, and David R. Peterson, 2007, Implied volatility and future portfolio returns, Journal of Banking and Finance 31, 31833199.

[6] Bollerslev, Tim, George Tauchen, and Hao Zhou, 2009, Expected stock returns and variance risk premia, Review of Financial Studies 22, 4463-4492.

[7] Brandt, Michale W., and Qiang Kang, 2004, On the relationship between the conditional mean and volatility of stock returns: A latent VAR approach, Journal of Financial Economics 72, 217-257.

[8] Campbell, John Y., 1987, Stock returns and the term structure, Journal of Financial Economics 18, 373-399. 
[9] Canina, L., and S. Figlewski, 1993, The informational content of implied volatility, Review of Financial Studies 6, 659-681.

[10] Chang, Bo Young, Peter Christoffersen, and Kris Jacobs, 2013, Market skewness risk and the cross section of stock returns, Journal of Financial Economics 107(1), 46-68.

[11] Conrad, Jennifer, Robert F. Dittmar, and Eric Ghysels, 2013, Ex ante skewness and expected stock returns, Journal of Finance 68(1), 85-124.

[12] Cox, John C., Jonathan E. Ingersoll, Jr., and Stephen A. Ross, 1985, An intertemporal general equilibrium model of asset prices, Econometrica 53, 363-384.

[13] Diacogiannis, George, and David Feldman, 2010, The CAPM relation for inefficient portfolios, Working paper, University of New South Wales.

[14] Dumas, Bernard, 1989, Two-person dynamic equilibrium in the capital market, Review of Financial Studies 2, 157-188.

[15] Glosten, Lawrence R., Ravi Jagannathan, and David E. Runkle, 1993, On the relation between the expected value and the volatility of the nominal excess return on stocks, Journal of Finance 48, 1779-1801.

[16] Guo, Hui, and Robert F. Whitelaw, 2006, Uncovering the risk-return relationship in the stock market, Journal of Finance 61, 1433-1463.

[17] Harrison, Paul, and Harold H. Zhang, 1999, An investigation of the risk and return relation at long horizons, Review of Economics and Statistics 81, 399-408.

[18] Harvey, Campbell R., and Akhtar Siddique, 2000a, Conditional skewness in asset pricing tests, Journal of Finance 55, 1263-1295. 
[19] Harvey, Campbell R., and Akhtar Siddique, 2000b, Time-varying conditional skewness and the market risk premium, Working paper, Duke University.

[20] Lettau, Martin, and Sydney Ludvigson, 2001, Consumption, aggregate wealth, and expected stock returns, Journal of Finance 56, 815-849.

[21] Martin, Ian W. R., 2013, Consumption-based asset pricing with higher cumulants, Review of Economic Studies 80, 745-773.

[22] Mitton, Todd, and Keith Vorkink, 2007, Equilibrium underdiversification and the preference for skewness, Review of Financial Studies 20, 1255-1288.

[23] Turner, Christopher M., Richard Startz, and Charles R. Nelson, 1989, A Markov model of heteroskedasticity, risk, and learning in the stock market, Journal of Financial Economics 25, 3-22.

[24] Vasicek, Oldrich Alfons, 2005, The economics of interest rate, Journal of Financial Economics 76, 293-307.

[25] Zhang, Jin E., Huimin Zhao, and Eric C. Chang, 2012, Equilibrium asset and option pricing under jump diffusion, Mathematical Finance, 22, 538-568. 


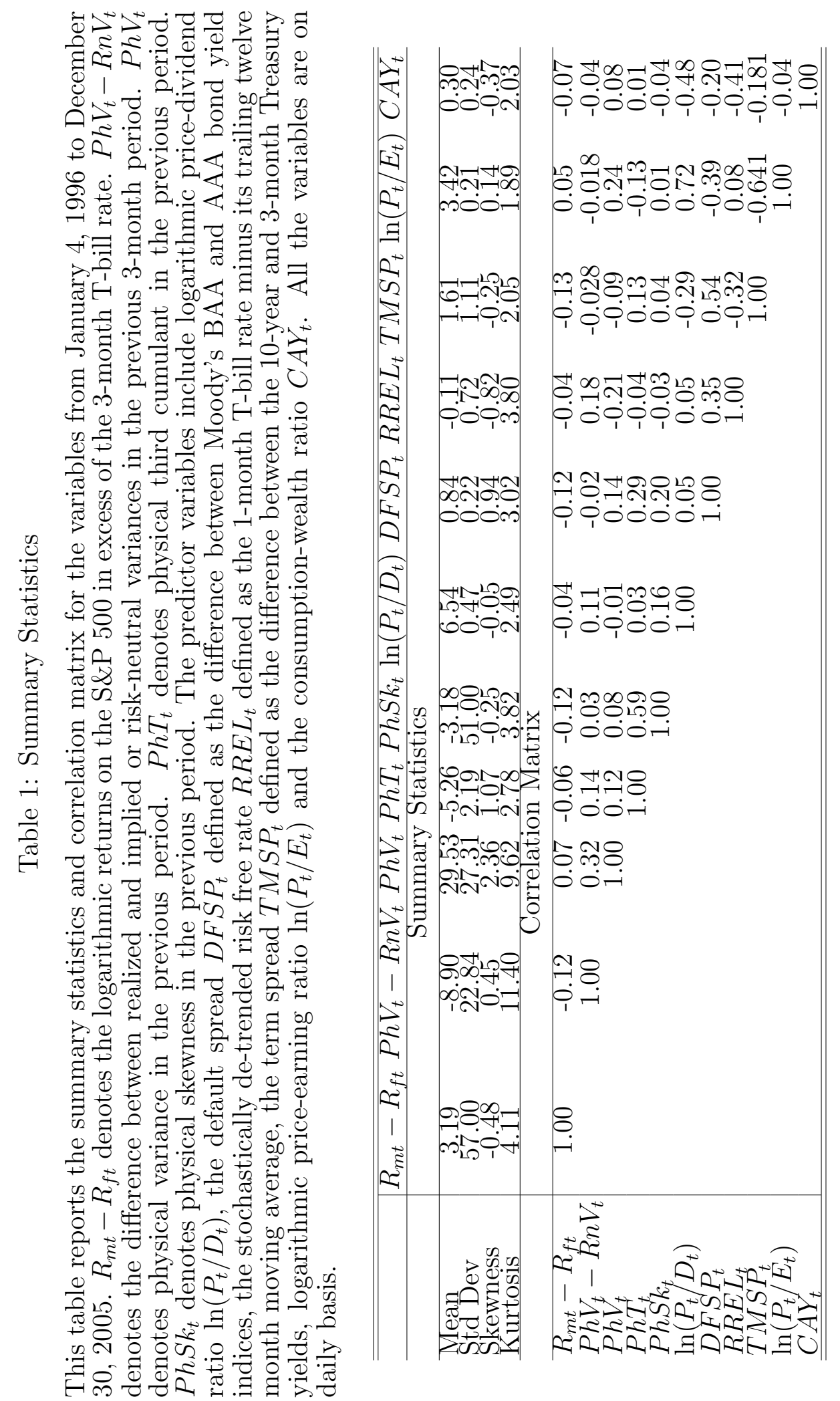


Table 2: Monthly Return Regressions

This table reports the regression results for annualized 1-month excess returns on different predicting variables. The sample period extends from January 4, 1996 to December 30, 2005. Variables calculated are on monthly basis. Newey-West adjusted t-statistics are reported in parentheses. $P h V_{t+1}$ and $P h T_{t+1}$ denote realized variance and the third cumulant in the current period. The definitions of other variables are the same as those in Table 1. Panel A reports the regressions for single variable and Panel B reports the regressions for multiple variables.

Panel A: Regressions for Single Variable

\begin{tabular}{|c|c|c|c|c|c|c|c|c|c|c|c|c|c|}
\hline & \multicolumn{13}{|c|}{ Single } \\
\hline Constant & $\begin{array}{l}-0.01 \\
(-0.18)\end{array}$ & $\begin{array}{l}0.16 \\
(3.15)\end{array}$ & $\begin{array}{l}-0.08 \\
(-1.47)\end{array}$ & $\begin{array}{l}0.04 \\
(0.88)\end{array}$ & $\begin{array}{c}0.04 \\
(1.06)\end{array}$ & $\begin{array}{l}0.03 \\
(0.75)\end{array}$ & $\begin{array}{l}-0.01 \\
(-0.18)\end{array}$ & $\begin{array}{l}0.01 \\
(0.20)\end{array}$ & $\begin{array}{l}1.76 \\
(3.46)\end{array}$ & $\begin{array}{l}0.17 \\
0.96)\end{array}$ & $\begin{array}{l}0.04 \\
(0.64)\end{array}$ & $\begin{array}{l}0.05 \\
(0.99)\end{array}$ & $\begin{array}{l}0.92 \\
(1.45)\end{array}$ \\
\hline $\begin{array}{l}P h V_{t} \\
P h V_{t+1}\end{array}$ & $\begin{array}{c}0.13 \\
(0.93)\end{array}$ & -0.42 & & & & & & & & & & & \\
\hline$R n V_{t}$ & & $(-2.29)$ & $\begin{array}{l}0.31 \\
(2.39)\end{array}$ & & & & & & & & & & \\
\hline$P h T_{t}$ & & & & $\begin{array}{l}-0.01 \\
(-0.98)\end{array}$ & & & & & & & & & \\
\hline$P h T_{t+1}$ & & & & & $\begin{array}{c}0.13 \\
(0.48)\end{array}$ & & & & & & & & \\
\hline$P h S k_{t}$ & & & & & & $\begin{array}{l}-0.13 \\
(-1.91)\end{array}$ & & & & & & & \\
\hline$R n T_{t}$ & & & & & & & $\begin{array}{l}-0.09 \\
(-2.04)\end{array}$ & & & & & & \\
\hline$P h V_{t}-R n V_{t}$ & & & & & & & & $\begin{array}{l}-0.29 \\
(-2.51)\end{array}$ & & & & & \\
\hline $\ln \left(P_{t} / D_{t}\right)$ & & & & & & & & & $\begin{array}{l}-2.58 \\
(-3.37)\end{array}$ & & & & \\
\hline$D F S P_{t}$ & & & & & & & & & & $\begin{array}{l}-1.57 \\
(-0.76)\end{array}$ & & & \\
\hline$R R E L_{t}$ & & & & & & & & & & & $\begin{array}{c}3.87 \\
(0.64)\end{array}$ & & \\
\hline$T M S P_{t}$ & & & & & & & & & & & & $\begin{array}{l}-0.89 \\
(-0.22)\end{array}$ & \\
\hline $\ln \left(P_{t} / E_{t}\right)$ & & & & & & & & & & & & & $\begin{array}{l}-2.63 \\
(-1.86)\end{array}$ \\
\hline $\operatorname{Adj.}^{2}(\%)$ & 0.49 & 0.04 & 2.50 & 0.29 & 0.20 & 1.31 & 1.52 & 0.29 & 4.58 & 0.38 & 0.20 & -0.01 & 0.84 \\
\hline
\end{tabular}


Panel B: Regressions for Multiple Variables

\begin{tabular}{|c|c|c|c|c|c|c|c|c|c|c|c|}
\hline & \multicolumn{11}{|c|}{ Multiple } \\
\hline Constant & $\begin{array}{l}-0.14 \\
(-0.26)\end{array}$ & $\begin{array}{c}1.98 \\
(3.75)\end{array}$ & $\begin{array}{l}0.16 \\
(3.86)\end{array}$ & $\begin{array}{c}1.29 \\
(2.65)\end{array}$ & $\begin{array}{l}1.58 \\
(2.24)\end{array}$ & $\begin{array}{c}0.99 \\
(1.49)\end{array}$ & $\begin{array}{l}-0.02 \\
(-0.37)\end{array}$ & $\begin{array}{c}0.05 \\
(0.13) \\
\end{array}$ & $\begin{array}{c}-0.09 \\
(-1.69) \\
\end{array}$ & $\begin{array}{c}0.01 \\
(0.25)\end{array}$ & $\begin{array}{c}0.09 \\
(1.44)\end{array}$ \\
\hline$P h V_{t}$ & $\begin{array}{l}1.72 \\
(1.06)\end{array}$ & 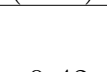 & & & & & $\begin{array}{l}1.67 \\
(1.05)\end{array}$ & & & & $\begin{array}{l}1.88 \\
(1.11)\end{array}$ \\
\hline$P h V_{t+1}$ & & $\begin{array}{l}-0.42 \\
(-2.37)\end{array}$ & $\begin{array}{l}-0.44 \\
(-2.84)\end{array}$ & $\begin{array}{l}-0.44 \\
(-2.76)\end{array}$ & & & & & & & \\
\hline$R n V_{t}$ & & & & & $\begin{array}{c}0.39 \\
(2.63)\end{array}$ & & & & $\begin{array}{c}0.34 \\
(1.72)\end{array}$ & & \\
\hline$P h T_{t}$ & $\begin{array}{l}-0.17 \\
(-1.29)\end{array}$ & & & & & & & & & $\begin{array}{l}-0.11 \\
(-0.67)\end{array}$ & \\
\hline$P h T_{t+1}$ & & & $\begin{array}{c}0.20 \\
(1.05)\end{array}$ & $\begin{array}{c}0.20 \\
(1.05)\end{array}$ & & & & & & & \\
\hline$P h S k_{t}$ & & & & & & & $\begin{array}{l}-0.14 \\
(-1.99)\end{array}$ & $\begin{array}{l}-0.12 \\
(-1.88)\end{array}$ & & & $\begin{array}{l}-0.14 \\
(-2.04)\end{array}$ \\
\hline$R n T_{t}$ & & & & & & $\begin{array}{l}-0.09 \\
(-204)\end{array}$ & & & $\begin{array}{c}0.16 \\
(0.22)\end{array}$ & & \\
\hline$P h V_{t}-R n V_{t}$ & & & & & & & & $\begin{array}{l}-0.28 \\
(-2.39)\end{array}$ & & $\begin{array}{l}-0.28 \\
(-2.34)\end{array}$ & \\
\hline $\ln \left(P_{t} / D_{t}\right)$ & & $\begin{array}{l}-2.84 \\
(-3.34)\end{array}$ & & & & & & & & & \\
\hline$D F S P_{t}$ & & $\begin{array}{l}1.85 \\
(0.87)\end{array}$ & & & & & & & & & \\
\hline$R R E L_{t}$ & & 2.71 & & -1.99 & 7.81 & & & & & & \\
\hline$T M S P_{t}$ & & $\begin{array}{l}(0.04) \\
-7.47 \\
(-1.83)\end{array}$ & & $(-2.34)$ & $\begin{array}{l}1.10) \\
-4.17 \\
(-0.81)\end{array}$ & & & & & & \\
\hline $\ln \left(P_{t} / E_{t}\right)$ & & & & $\begin{array}{l}-4.38 \\
(-2.31)\end{array}$ & $\begin{array}{l}-4.71 \\
(-2.22)\end{array}$ & $\begin{array}{l}-2.94 \\
(-1.52)\end{array}$ & & & & & $\begin{array}{l}-2.77 \\
(-1.44)\end{array}$ \\
\hline $\operatorname{Adj.R^{2}(\% )}$ & 0.97 & 8.61 & 4.59 & 6.15 & 5.29 & 22.60 & 2.03 & 2.59 & 2.48 & 1.51 & 3.03 \\
\hline
\end{tabular}


Table 3: Quarterly Return Regressions

This table reports the regression results for annualized 3-month excess returns on different predicting variables. The sample period extends from January 1996 to December 2005. Variables calculated are on 3-month basis. Newey-West adjusted t-statistics are reported in parentheses. $P h V_{t+1}$ and $P h T_{t+1}$ denote realized variance and the third cumulant in the current period. The definitions of other variables are the same as those in Table 1. Panel A reports the regressions for single variable and Panel B reports the regressions for multiple variables.

Panel A: Regressions for Single Variable

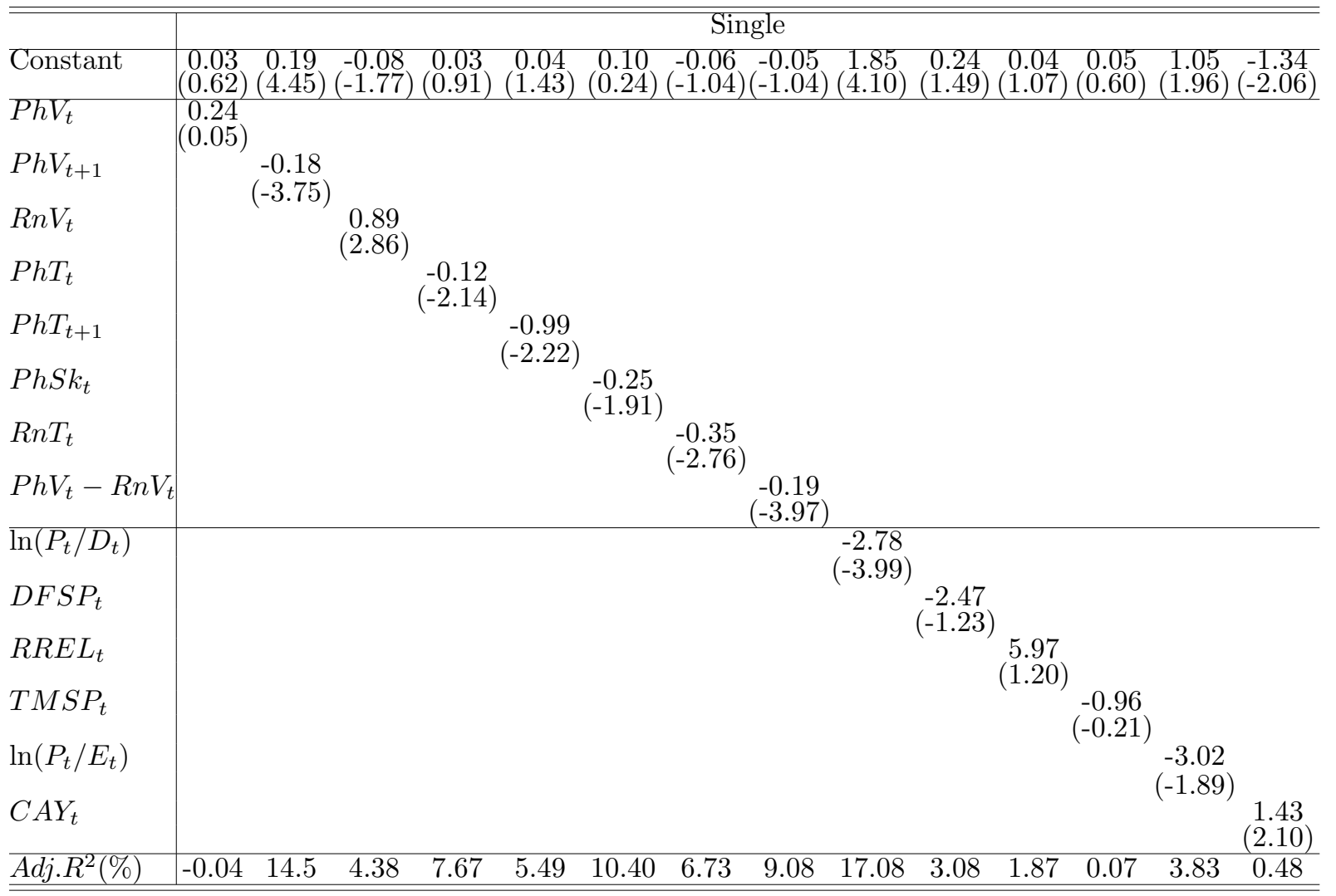


Panel B: Regressions for Multiple Variables

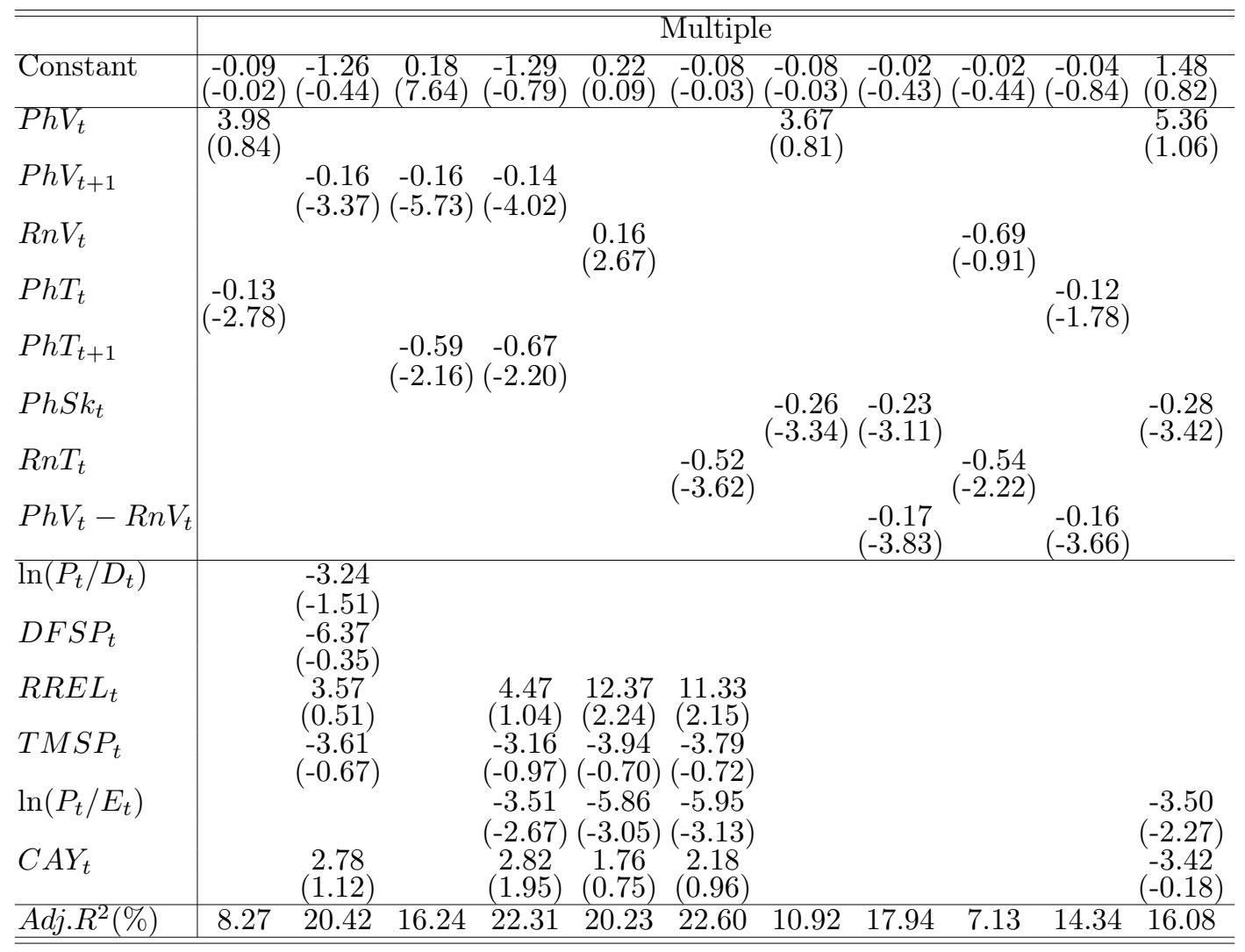


Table 4: Semiannual Return Regressions

This table reports the regression results for annualized 6-month excess returns on different predicting variables. The sample period extends from January 1996 to December 2005. Variables calculated are on 6-month basis. Newey-West adjusted t-statistics are reported in parentheses. $P h V_{t+1}$ and $P h T_{t+1}$ denote realized variance and the third cumulant in the current period. The definitions of other variables are the same as those in Table 1. Panel A reports the regressions for single variable and Panel B reports the regressions for multiple variables.

Panel A: Regressions for Single Variable

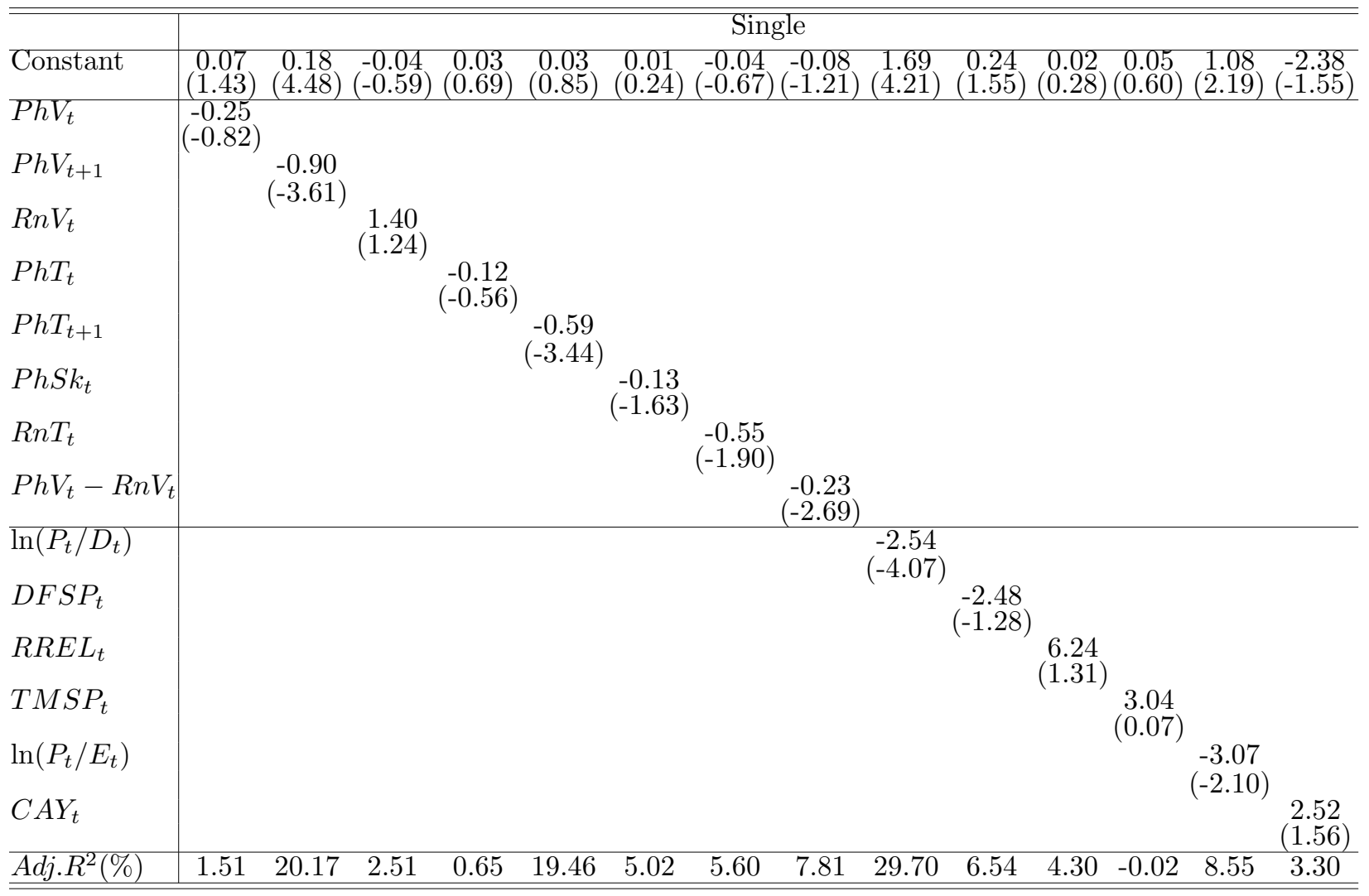


Panel B: Regressions for Multiple Variables

\begin{tabular}{|c|c|c|c|c|c|c|c|c|c|c|}
\hline & \multicolumn{10}{|c|}{$\begin{array}{ll}\text { Multiple } \\
\end{array}$} \\
\hline Constant & $\begin{array}{l}0.06 \\
(1.29)\end{array}$ & $\begin{array}{l}0.82 \\
(0.34)\end{array}$ & $\begin{array}{l}0.14 \\
(3.67)\end{array}$ & $\begin{array}{l}-3.09 \\
(-1.85)\end{array}$ & $\begin{array}{l}-2.68 \\
(-1.54)\end{array}$ & $\begin{array}{l}-2.98 \\
(-1.82)\end{array}$ & $\begin{array}{cc}-0.03 & -0.10 \\
(-0.62) & (-1.54)\end{array}$ & $\begin{array}{l}0.01 \\
(0.08)\end{array}$ & $\begin{array}{l}-0.08 \\
(-1.17)\end{array}$ & $\begin{array}{l}-0.39 \\
-0.24)\end{array}$ \\
\hline$P h V_{t}$ & $\begin{array}{l}-0.22 \\
(-0.66)\end{array}$ & & & & & & $\begin{array}{l}-1.15 \\
(-0.37)\end{array}$ & & & $\begin{array}{l}-0.26 \\
(-0.10)\end{array}$ \\
\hline$P h V_{t+1}$ & & $\begin{array}{l}-0.46 \\
(-2.09)\end{array}$ & $\begin{array}{c}-0.66 \\
(-3.14)\end{array}$ & $\begin{array}{c}-0.37 \\
(-1.83)\end{array}$ & & & & & & \\
\hline$R n V_{t}$ & & & & & $\begin{array}{c}0.38 \\
(2.32)\end{array}$ & & & $\begin{array}{l}-0.23 \\
(-1.43)\end{array}$ & & \\
\hline$P h T_{t}$ & $\begin{array}{l}-0.65 \\
(-0.37)\end{array}$ & & & & & & & & $\begin{array}{l}-0.12 \\
(-1.78)\end{array}$ & \\
\hline$P h T_{t+1}$ & & & $\begin{array}{l}-0.43 \\
(-2.88)\end{array}$ & $\begin{array}{l}-0.53 \\
(-3.74)\end{array}$ & & & & & & \\
\hline$P h S k_{t}$ & & & & & & & $\begin{array}{cc}-0.12 & -0.12 \\
(-1.50) & (-1.62)\end{array}$ & & & $\begin{array}{l}-0.13 \\
(-1.59)\end{array}$ \\
\hline$R n T_{t}$ & & & & & & $\begin{array}{l}-1.16 \\
(-3.94)\end{array}$ & & $\begin{array}{l}-1.09 \\
(-2.40)\end{array}$ & & \\
\hline$P h V_{t}-R n V_{t}$ & & & & & & & $\begin{array}{l}-0.31 \\
(-3.24)\end{array}$ & & $\begin{array}{l}-0.32 \\
(-2.62)\end{array}$ & \\
\hline $\ln \left(P_{t} / D_{t}\right)$ & & $\begin{array}{l}-2.07 \\
(-204)\end{array}$ & & & & & & & & \\
\hline$D F S P_{t}$ & & $\begin{array}{l}-8.93 \\
(-0.95)\end{array}$ & & & & & & & & \\
\hline$R R E L_{t}$ & & 4.48 & & $\begin{array}{l}8.85 \\
(194)\end{array}$ & 14.88 & $\begin{array}{l}13.52 \\
(3.70)\end{array}$ & & & & \\
\hline$T M S P_{t}$ & & $\begin{array}{l}-4.78 \\
(-0.18)\end{array}$ & & $\begin{array}{l}2.34 \\
(0.64)\end{array}$ & $\begin{array}{l}-2.12 \\
(-0.05)\end{array}$ & $\begin{array}{l}-3.58 \\
(-0.09)\end{array}$ & & & & \\
\hline $\ln \left(P_{t} / E_{t}\right)$ & & & & -2.60 & -5.07 & -5.54 & & & & -3.37 \\
\hline$C A Y_{t}$ & & $\begin{array}{l}7.66 \\
(0.37)\end{array}$ & & $\begin{array}{c}(-1.94) \\
4.23 \\
(2.84)\end{array}$ & $\begin{array}{c}(-2.74) \\
4.45 \\
(2.56)\end{array}$ & $\begin{array}{c}(-3.40) \\
4.99 \\
(3.06)\end{array}$ & & & & $\begin{array}{c}(-2.20) \\
1.63 \\
(1.01)\end{array}$ \\
\hline $\operatorname{Adj.} R^{2}(\%)$ & 1.64 & 40.88 & 28.70 & 44.60 & 37.22 & 43.38 & 12.43 & 6.97 & 7.97 & 17.00 \\
\hline
\end{tabular}




\section{Table 5: Annual Return Regressions}

This table reports the regression results for annual excess returns on different predicting variables. The sample period extends from January 1996 to December 2005. Variables calculated are on 12month basis. Newey-West adjusted t-statistics are reported in parentheses. $P h V_{t+1}$ and $P h T_{t+1}$ denote realized variance and the third cumulant in the current period. The definitions of other variables are the same as those in Table 1. Panel A reports the regressions for single variable and Panel B reports the regressions for multiple variables.

Panel A: Regressions for Single Variables

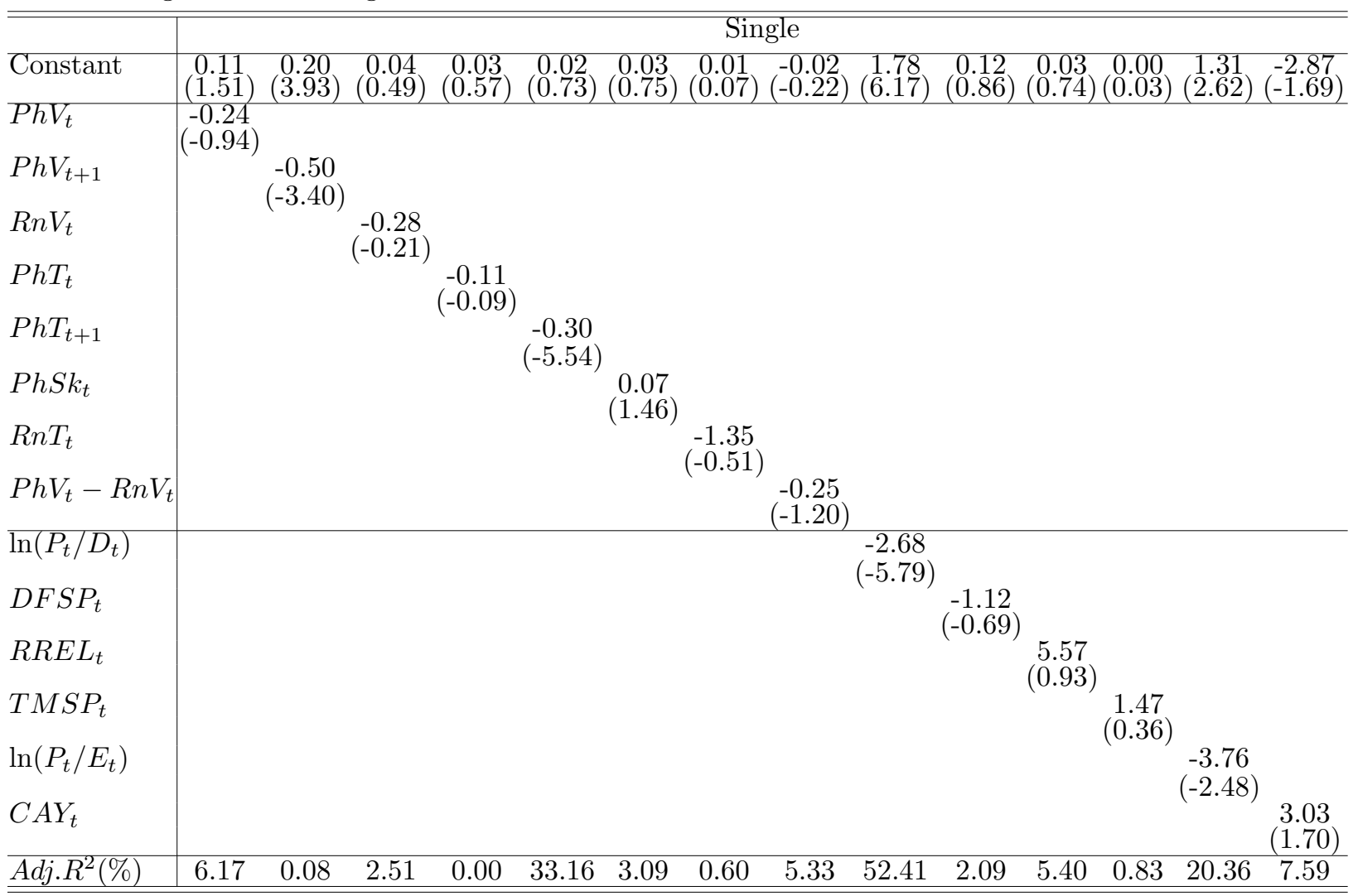


Panel B: Regressions for Multiple Variables

\begin{tabular}{|c|c|c|c|c|c|c|c|c|c|c|c|}
\hline & \multicolumn{11}{|c|}{ Multiple } \\
\hline Constant & $\begin{array}{c}0.12 \\
(2.04)\end{array}$ & $\begin{array}{l}-0.60 \\
(-0.24)\end{array}$ & $\begin{array}{c}0.14 \\
(3.65)\end{array}$ & $\begin{array}{l}-2.04 \\
(-1.78)\end{array}$ & $\begin{array}{l}-3.46 \\
(-3.07)\end{array}$ & $\begin{array}{l}-2.89 \\
(-2.51) \\
\end{array}$ & $\begin{array}{c}0.11 \\
(1.78)\end{array}$ & $\begin{array}{c}-0.01 \\
(-0.20)\end{array}$ & $\begin{array}{c}0.06 \\
(1.49)\end{array}$ & $\begin{array}{l}-0.03 \\
(-0.43)\end{array}$ & $\begin{array}{l}-1.30 \\
(-1.28)\end{array}$ \\
\hline$P h V_{t}$ & $\begin{array}{l}2.84 \\
(3.65)\end{array}$ & & & & & & $\begin{array}{l}-2.36 \\
(-1.01)\end{array}$ & & & & $\begin{array}{l}-1.75 \\
(-1.19)\end{array}$ \\
\hline$P h V_{t+1}$ & & $\begin{array}{l}-0.27 \\
(-2.24)\end{array}$ & $\begin{array}{l}-0.34 \\
(-2.91)\end{array}$ & $\begin{array}{c}-1.12 \\
(-0.78)\end{array}$ & & & & & & & \\
\hline$R n V_{t}$ & & & & & $\begin{array}{l}0.30 \\
(2.78)\end{array}$ & & & & $\begin{array}{l}-0.25 \\
(-1.53)\end{array}$ & & \\
\hline$P h T_{t}$ & $\begin{array}{c}0.95 \\
0.73)\end{array}$ & & & & & & & & & $\begin{array}{l}-0.12 \\
(-1.78)\end{array}$ & \\
\hline$P h T_{t+1}$ & & & $\begin{array}{c}-0.22 \\
(-4.42)\end{array}$ & $\begin{array}{c}-0.25 \\
(-3.89)\end{array}$ & & & & & & & \\
\hline & & & & & & & $\begin{array}{c}0.07 \\
(1.30)\end{array}$ & $\begin{array}{c}0.08 \\
(1.72)\end{array}$ & & & $\begin{array}{c}0.05 \\
(1.34)\end{array}$ \\
\hline$R n T_{t}$ & & & & & & $\begin{array}{l}-0.79 \\
(-4.25)\end{array}$ & & & $\begin{array}{l}-0.56 \\
(-1.89)\end{array}$ & & \\
\hline$P h V_{t}-R n V_{t}$ & & & & & & & & $\begin{array}{l}-0.31 \\
(-3.24)\end{array}$ & & $\begin{array}{l}-0.27 \\
(-1.51)\end{array}$ & \\
\hline $\ln \left(P_{t} / D_{t}\right)$ & & $\begin{array}{l}-2.00 \\
(-273)\end{array}$ & & & & & & & & & \\
\hline$D F S P_{t}$ & & $\begin{array}{c}4.69 \\
(0.56)\end{array}$ & & & & & & & & & \\
\hline$R R E L_{t}$ & & $\begin{array}{l}5.31 \\
(1.29)\end{array}$ & & $\begin{array}{c}5.42 \\
(1.10)\end{array}$ & 13.20 & $\begin{array}{c}9.33 \\
2.73)\end{array}$ & & & & & \\
\hline$T M S P_{t}$ & & -5.03 & & 2.80 & $\begin{array}{l}-2.47 \\
(-0.08)\end{array}$ & -2.39 & & & & & \\
\hline $\ln \left(P_{t} / E_{t}\right)$ & & & & -2.83 & -5.43 & $\begin{array}{l}-0.00) \\
-6.42\end{array}$ & & & & & -3.41 \\
\hline$C A Y_{t}$ & & $\begin{array}{c}2.09 \\
(0.97)\end{array}$ & & $\begin{array}{c}(-2.05) \\
3.06 \\
(3.17)\end{array}$ & $\begin{array}{c}(-4.46) \\
5.45 \\
(4.56)\end{array}$ & $\begin{array}{c}(-5.42) \\
5.27 \\
(4.67)\end{array}$ & & & & & $\begin{array}{c}(-2.26) \\
2.67 \\
(13.09)\end{array}$ \\
\hline $\operatorname{Adj.R}^{2}(\%)$ & 6.85 & 40.88 & 44.49 & 64.69 & 54.45 & 59.40 & 9.16 & 9.48 & 3.71 & 7.29 & 31.90 \\
\hline
\end{tabular}




\section{Table 6: Regressions for Variance Risk Premium}

This table reports the regression results for variance risk premium on physical skewness and third cumulant on 1-month, 3-month, 6-month and 12-month basis respectively. The regression equation is: $P h V_{t}-R n V_{t}=a+b P h T_{t} / P h S k_{t}+e_{t}$. The sample period extends from January 4, 1996 to December 30, 2005. Newey-West adjusted t-statistics are reported in parentheses. The definitions of all variables are the same as those in Table 1.

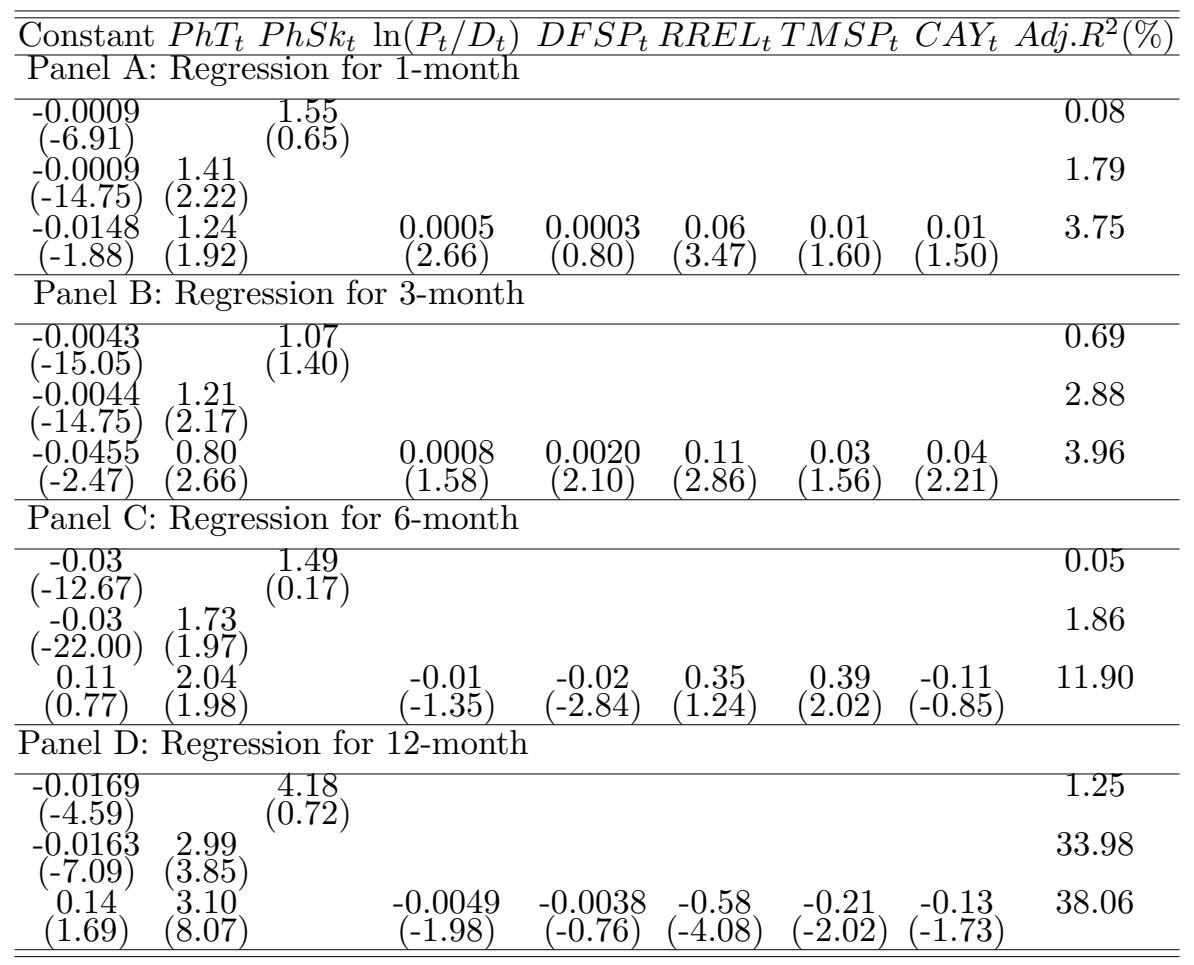


Table 7: Regressions for Bear Market

This table reports the regression results for excess returns on physical variance and third cumulant for bear market on 1-month, 3-month, 6-month and 12-month basis respectively. The regression equation is: $E x R_{t+1}=a+b P h V_{t}+c P h T_{t}+e_{t}$. The sample period extends from March 24, 2000 to October 9, 2002. Newey-West adjusted t-statistics are reported in parentheses. The definitions of all variables are the same as those in Table 1.

\begin{tabular}{|c|c|c|c|c|c|c|c|c|}
\hline \multirow{2}{*}{\multicolumn{9}{|c|}{$\begin{array}{cccc}\text { Constant } & P h V_{t} & P h T_{t} & \ln \left(P_{t} / D_{t}\right)\end{array}$}} \\
\hline & & sion for & & & & & & \\
\hline $\begin{array}{c}-0.51 \\
-366\end{array}$ & $\begin{array}{l}0.58 \\
(189)\end{array}$ & & & & & & & 6.65 \\
\hline-0.55 & 0.74 & -0.38 & & & & & & 8.62 \\
\hline $\begin{array}{c}(-5.01) \\
0.40 \\
(4.04)\end{array}$ & $\begin{array}{l}2.88) \\
(3.25)\end{array}$ & $\begin{array}{l}(-1.91) \\
-0.11 \\
(-0.58)\end{array}$ & $\begin{array}{l}-4.15 \\
(-1.52)\end{array}$ & $\begin{array}{l}8.47 \\
(2.01)\end{array}$ & $\begin{array}{l}-5.09 \\
(-4.32)\end{array}$ & $\begin{array}{l}-4.18 \\
(-3.31)\end{array}$ & $\begin{array}{l}-4.01 \\
(-4.09)\end{array}$ & 18.41 \\
\hline
\end{tabular}

Panel B: Regression for 3-month

\begin{tabular}{|c|c|c|c|c|c|c|c|c|}
\hline $\begin{array}{l}-0.54 \\
-4.44)\end{array}$ & $\begin{array}{c}0.23 \\
3.96)\end{array}$ & & & & & & & 18.98 \\
\hline-0.62 & $\begin{array}{c}0.32 \\
(4.29\end{array}$ & $(-0.11$ & & & & & & 24.29 \\
\hline $\begin{array}{c}(.88) \\
(2.80)\end{array}$ & $\begin{array}{c}(4.29) \\
0.23 \\
(3.96)\end{array}$ & $\begin{array}{l}-0.16 \\
(-3.79)\end{array}$ & $\begin{array}{l}-8.20 \\
(-5.83)\end{array}$ & $\begin{array}{l}5.25 \\
(2.15)\end{array}$ & $\begin{array}{l}-2.26 \\
(-2.56)\end{array}$ & $\begin{array}{l}-3.37 \\
(-3.76)\end{array}$ & $\begin{array}{l}-1.43 \\
(-2.18)\end{array}$ & 55.09 \\
\hline
\end{tabular}

Panel C: Regression for 6-month

\begin{tabular}{|c|c|c|c|c|c|c|c|c|}
\hline $\begin{array}{c}-0.50 \\
(-4.32) \\
-0.45 \\
(-4.19) \\
-3.99 \\
(-0.94) \\
\end{array}$ & $\begin{array}{l}1.10 \\
(2.81) \\
0.84 \\
(2.18) \\
0.67 \\
(2.99) \\
\end{array}$ & $\begin{array}{c}0.21 \\
(1.50) \\
-0.38 \\
(-1.94) \\
\end{array}$ & $\begin{array}{l}-3.90 \\
(-4.90) \\
\end{array}$ & $\begin{array}{l}-2.55 \\
(-1.81) \\
\end{array}$ & $\begin{array}{c}-3.22 \\
(-0.10) \\
\end{array}$ & $\begin{array}{l}-4.66 \\
(-1.9) \\
\end{array}$ & $\begin{array}{c}6.85 \\
(1.69) \\
\end{array}$ & $\begin{array}{l}15.38 \\
17.68 \\
55.07\end{array}$ \\
\hline \multicolumn{9}{|c|}{ Panel D: Regression for 12-month } \\
\hline $\begin{array}{c}-0.60 \\
(-1.98) \\
-0.46 \\
(-1.36) \\
-6.14 \\
(-2.34)\end{array}$ & $\begin{array}{l}0.88 \\
(1.32) \\
0.54 \\
(0.75) \\
0.33 \\
(0.86) \\
\end{array}$ & $\begin{array}{c}0.16 \\
(0.81) \\
0.89 \\
(0.96)\end{array}$ & $\begin{array}{l}-1.26 \\
(-1.67)\end{array}$ & $\begin{array}{l}2.37 \\
(2.51)\end{array}$ & $\begin{array}{c}6.62 \\
(2.75)\end{array}$ & $\begin{array}{c}-9.20 \\
(-0.43)\end{array}$ & $\begin{array}{c}6.75 \\
(2.71)\end{array}$ & 12.42 \\
\hline
\end{tabular}


Table 8: Regressions for Bull Market

This table reports the regression results for excess returns on physical variance and third cumulant for bull market on 1-month, 3-month, 6-month and 12-month basis respectively. The regression equation is: $E x R_{t+1}=a+b P h V_{t}+c P h T_{t}+e_{t}$. The sample period extends from January 4, 1996 to March 23, 2000. Newey-West adjusted t-statistics are reported in parentheses. The definitions of all variables are the same as those in Table 1.

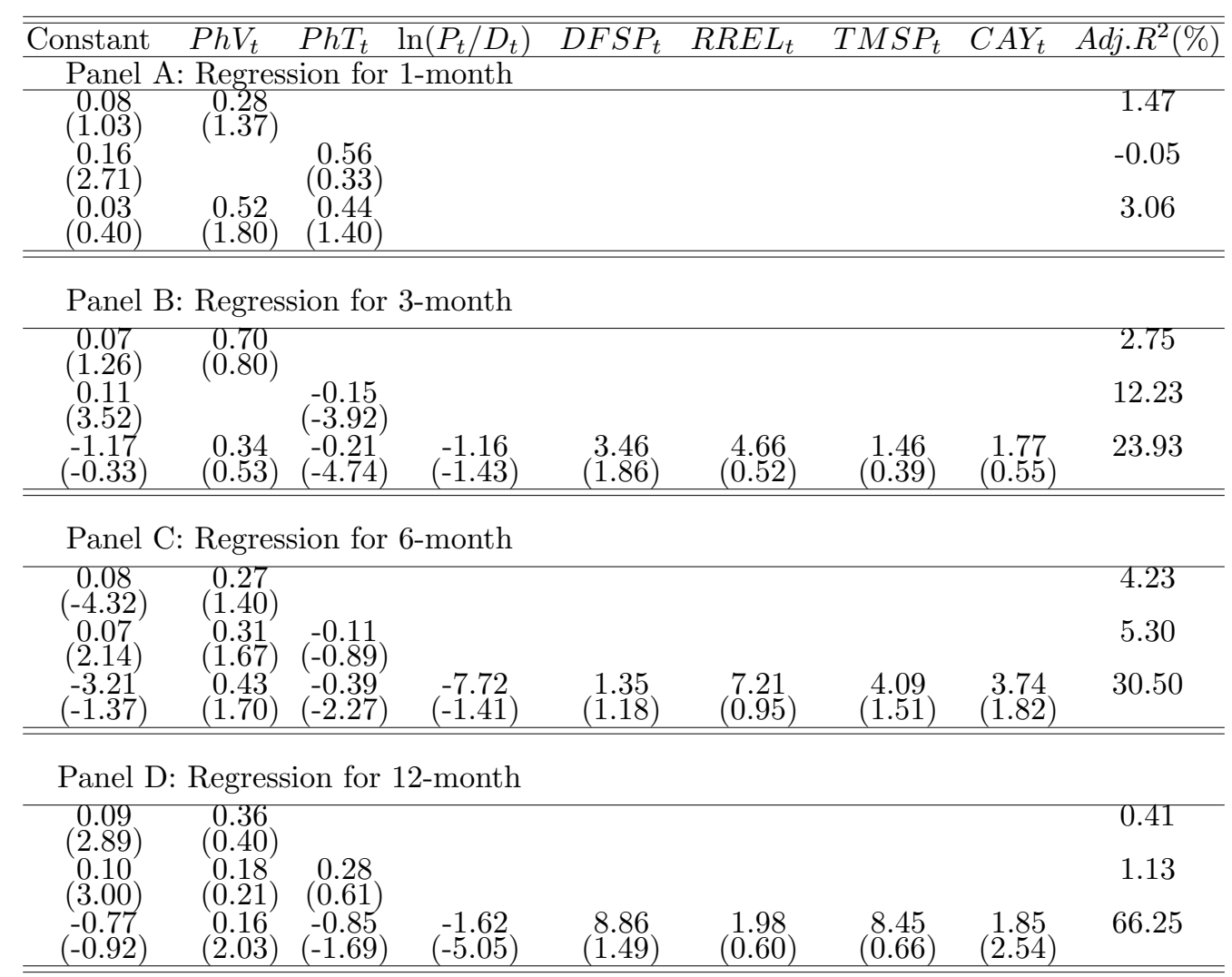

